\title{
Effect of Selenium on TNAZ Molecule - A DFT Treatment
}

\section{Lemi Türker}

Department of Chemistry, Middle East Technical University, Üniversiteler, Eskişehir Yolu No: 1, 06800 Çankaya/Ankara, Turkey; e-mail: 1turker@gmail.com; lturker@metu.edu.tr

\begin{abstract}
The present treatment deals with an unusual composite of TNAZ that is TNAZ+ $\mathrm{nSe}(\mathrm{n}: 1,2)$ within the constraints of density functional theory at the level of UB3LYP/6$31++G(d, p)$. TNAZ is an insensitive high explosive material. Since, selenium atom in its ground state has two unpaired electrons, the composites are considered in their singlet, triplet and quintet states. Selenium and TNAZ interact at different extents and the systems are electronically stable but TNAZ $+2 \mathrm{Se}$ (singlet) structurally decomposes by the elongation of one of the geminally substituted nitro groups. Modeling studies indicate that the $\mathrm{N}-\mathrm{O}$ bond elongation in the composite mentioned occurs only if azetidine ring is present with or without the nitramine bond. For the composites various structural, electronic and quantum chemical data have been harvested and discussed.
\end{abstract}

\section{Introduction}

1,3,3-trinitroazetidine, also known as TNAZ, is an energetic small-ring compound. Recently it is one of the most widely studied (both theoretically and experimentally) explosive [1-4]. The driving force for such an intensive research is to get more powerful but insensitive explosives. It is a highly nitrated (contains $\mathrm{N}-\mathrm{NO}_{2}$ and $\mathrm{C}-\mathrm{NO}_{2}$ groups) four membered nitrogen heterocyclic ring (azetidine). Reports reveal that it possesses improved performance in comparison to conventional 2,4,6-trinitrotoluene (TNT) which is a melt castable explosive. The presence of a small strained ring system contributes additional energy [5-10]. In the literature there are various methods reported for the synthesis of 1,3,3-trinitroazetidine [11].

Received: May 27, 2021; Accepted: July 1, 2021

Keywords and phrases: TNAZ, 1,3,3-trinitroazetidine, explosive, selenium, DFT.

Copyright (C) 2021 Lemi Türker. This is an open access article distributed under the Creative Commons Attribution License, which permits unrestricted use, distribution, and reproduction in any medium, provided the original work is properly cited. 
TNAZ has been proposed as potential replacement for 2,4,6-trinitrotoluene due to its high performance and melt castable properties [12]. Rather low melting point of TNAZ $\left(101^{\circ} \mathrm{C}\right)$ enables the processing of formulations on modified production lines. Its performance is approximately $30 \%$ greater than TNT. TNAZ shows excellent thermal stability $\left(>180^{\circ} \mathrm{C}\right)[13]$ in addition to its many advantages over various known explosives. TNAZ is a highly energetic material (more powerful than RDX) but less vulnerable to various stimuli than most other nitramines [14,15]. Unlike HMX, TNAZ is soluble in molten TNT and is compatible with various materials like aluminum, steel, brass and glass [16-18]. By using the pressure DSC method, the compatibility of 1,3,3trinitroazetidine (TNAZ) with various energetic components and inert materials of solid propellants was studied [19]. On the other hand, desensitization of TNAZ has been investigated theoretically via molecular structure modification [20].

In the present study, TNAZ and selenium composite (TNAZ+nSe; n:1,2) has been computationally studied within the realm of density functional theory (DFT). Selenium exists in two amorphous and three crystalline forms [21]. Its electronic configuration in the ground state is $[\mathrm{Ar}] \mathrm{d}^{10} 4 \mathrm{~s}^{2} 4 \mathrm{p}^{2} 4 \mathrm{p}^{1} 4 \mathrm{p}^{1}$. There are few examples of Se atom in the diagonal and trigonal valence state but there are many compounds in which it is tatrahedrally hybridized [21]. Boiling selenium contains $\mathrm{Se}_{8}$ molecules but above $1400^{\circ} \mathrm{C}$ only $\mathrm{Se}_{2}$ exists [22]. The common oxidation states of selenium are $-2,+4,+6$ [23]. Thus, interaction of an explosive, like TNAZ, with selenium having large span of oxidation states would be scientifically interesting.

\section{Method of Calculations}

The geometry optimizations of all the structures leading to energy minima were initially achieved by using MM2 method which were followed by semi-empirical PM3 self-consistent fields molecular orbital (SCF MO) method [24,25] at the unrestricted level $[26,27]$. The subsequent optimizations were achieved at Hartree-Fock level by using various basis sets. Then, geometry optimizations were managed within the framework of density functional theory $[28,29]$ at the level of UB3LYP/6-31++G(d,p) $[26,30]$. The exchange term of B3LYP consists of hybrid Hartree-Fock and local spin density (LSD) exchange functions with Becke's gradient correlation to LSD exchange [29,31]. The correlation term of B3LYP consists of the Vosko, Wilk, Nusair (VWN3) local correlation functional [32] and Lee, Yang, Parr (LYP) correlation correction functional [33]. The 
vibrational analyses were also done. The total electronic energies were corrected for the zero point vibrational energy (ZPE). The normal mode analysis for each structure yielded no imaginary frequencies for the $3 N-6$ vibrational degrees of freedom, where $N$ is the number of atoms in the system on the potential energy surface. This indicates that the structure of each molecule corresponds to at least a local minimum. All these calculations were done by using the Spartan 06 package program [34].

\section{Results and Discussion}

TNAZ molecule is 1,3,3-trinitro derivative of azetidine structure. Azetidine has rather strained 4-membered ring which could be considered as derived from cyclobutane obtained by means of monocentric carbon to nitrogen perturbation. Cyclopropane (has ring strain energy of $28 \mathrm{Kcal} / \mathrm{mol}$. [35]) and cyclobutane are structures of special type of hybridization having some $\pi$-type interaction [35]. Some of the results obtained presently could be explained based on that fact. The nitro groups of TNAZ (of which two of them are geminally substituted and the third one is a nitramine type) should be some interaction with each other through the skeleton.

On the other hand, selenium is also an interesting element which combines with many nonmetals and metals. It has two unpaired electrons in its $4 p$ atomic orbitals, thus may act as a reducing or oxidizing agent besides its various coordination possibilities [21].

In the present study, an unusual composite of TNAZ molecule with one or two of selenium atom(s) is/are considered. The composites exhibit various spin states. Figure 1 shows the optimized structures of them which also displays the direction of the dipole moment vectors. As seen in the figure in each case the vector originates somewhere around the geminally substituted nitro groups and tips to the nitramine moiety.

Table 1 shows some properties of the species presently considered. The data for TNAZ+2Se composites indicate that striking differences occur for their dipole moment values. Especially, the triplet state owes the lowest one whereas the singlet has the greatest dipole moment value in the group. Note that the singlet TNAZ+2Se possesses an elongated $\mathrm{N}-\mathrm{O}$ bond in one of the geminal nitro groups (see Figures 1 and 2). As seen in Figure 2, the azetidine $\mathrm{C}-\mathrm{C}$ bonds are comparable in length about the vertical plane passing through the nitrogen atom and $\mathrm{C}\left(\mathrm{NO}_{2}\right)_{2}$ moiety. The location of selenium atom(s) 
is/are all the time around the side of the geminal nitro groups. In TNAZ+2Se (singlet) case the distance between the Se atom and the oxygen atom of elongated N-O bond is $1.652 \AA$.

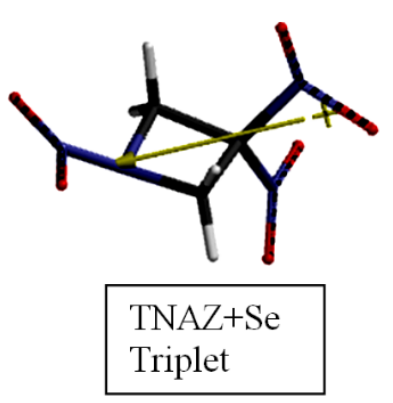

$\bullet$

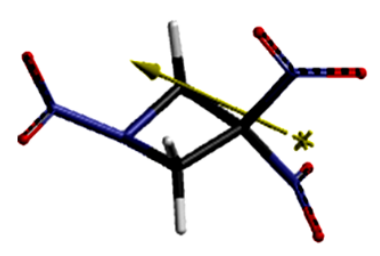

TNAZ+2Se Triplet
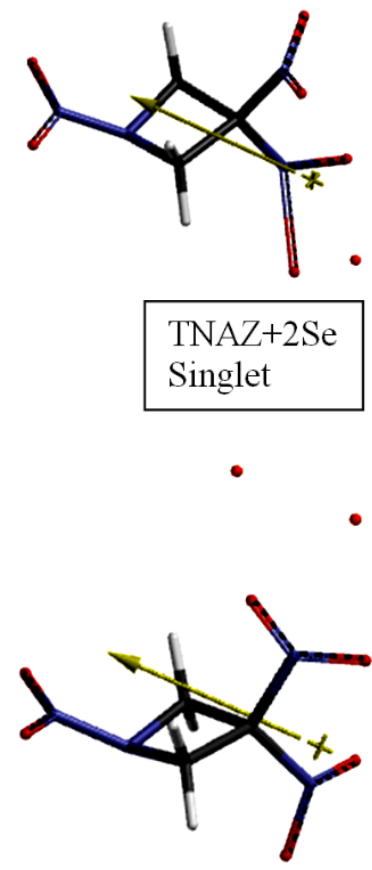

TNAZ+2Se Quintet

Figure 1. Optimized structures of the species considered.

Table 1. Some properties of the species considered.

\begin{tabular}{ccccc}
\hline Specie & $\begin{array}{c}\text { Area } \\
\left(\AA^{\mathbf{2}}\right)\end{array}$ & Volume $\left.\mathbf{(}^{\mathbf{3}}\right)$ & Ovality & $\begin{array}{c}\text { Dipole moment } \\
\text { (Debye) }\end{array}$ \\
\hline $\begin{array}{c}\text { TNAZ+Se } \\
\text { Triplet }\end{array}$ & 203.92 & 163.98 & 1.41 & 2.79 \\
$\begin{array}{c}\text { TNAZ+2Se } \\
\text { Singlet }\end{array}$ & 243.30 & 190.09 & 1.52 & 3.01 \\
$\begin{array}{c}\text { TNAZ+2Se } \\
\text { Triplet }\end{array}$ & 245.54 & 190.32 & 1.53 & 0.58 \\
$\begin{array}{c}\text { TNAZ+2Se } \\
\text { Quintet }\end{array}$ & 245.81 & 191.03 & 1.53 & 1.42 \\
\hline
\end{tabular}



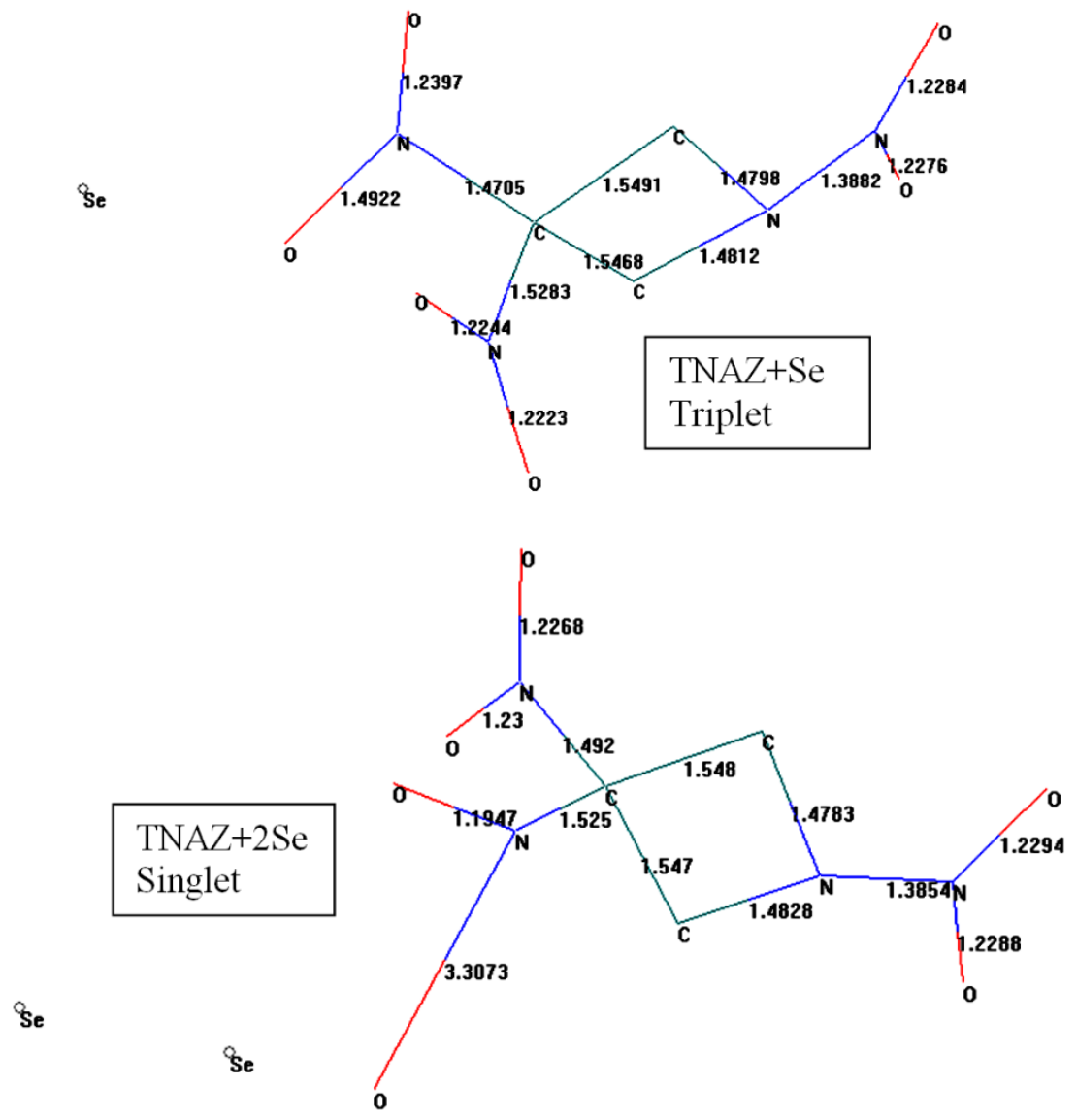

Se

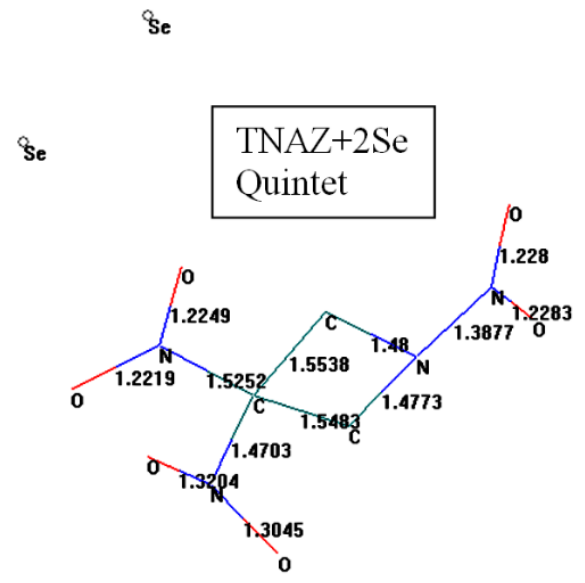

Figure 2. Calculated bond lengths of the species considered (Hydrogens omitted, in $\AA$ units). 
Figure 3 shows the electrostatic potential (ESP) charges on atoms of the species considered. The selenium atom(s) in all the cases are partially positively charged, except the case of TNAZ+2Se (singlet) where the selenium atom not nearby TNAZ is negatively (minute) charged. The selenium atoms in TNAZ+Se (triplet) and TNAZ+ 2Se (singlet) cases possess the greatest partial positive charge among the group. Note that these are all ESP charges and also note that the ESP charges are obtained by the program based on a numerical method that generates charges that reproduce the electrostatic potential field from the entire wavefunction [34].
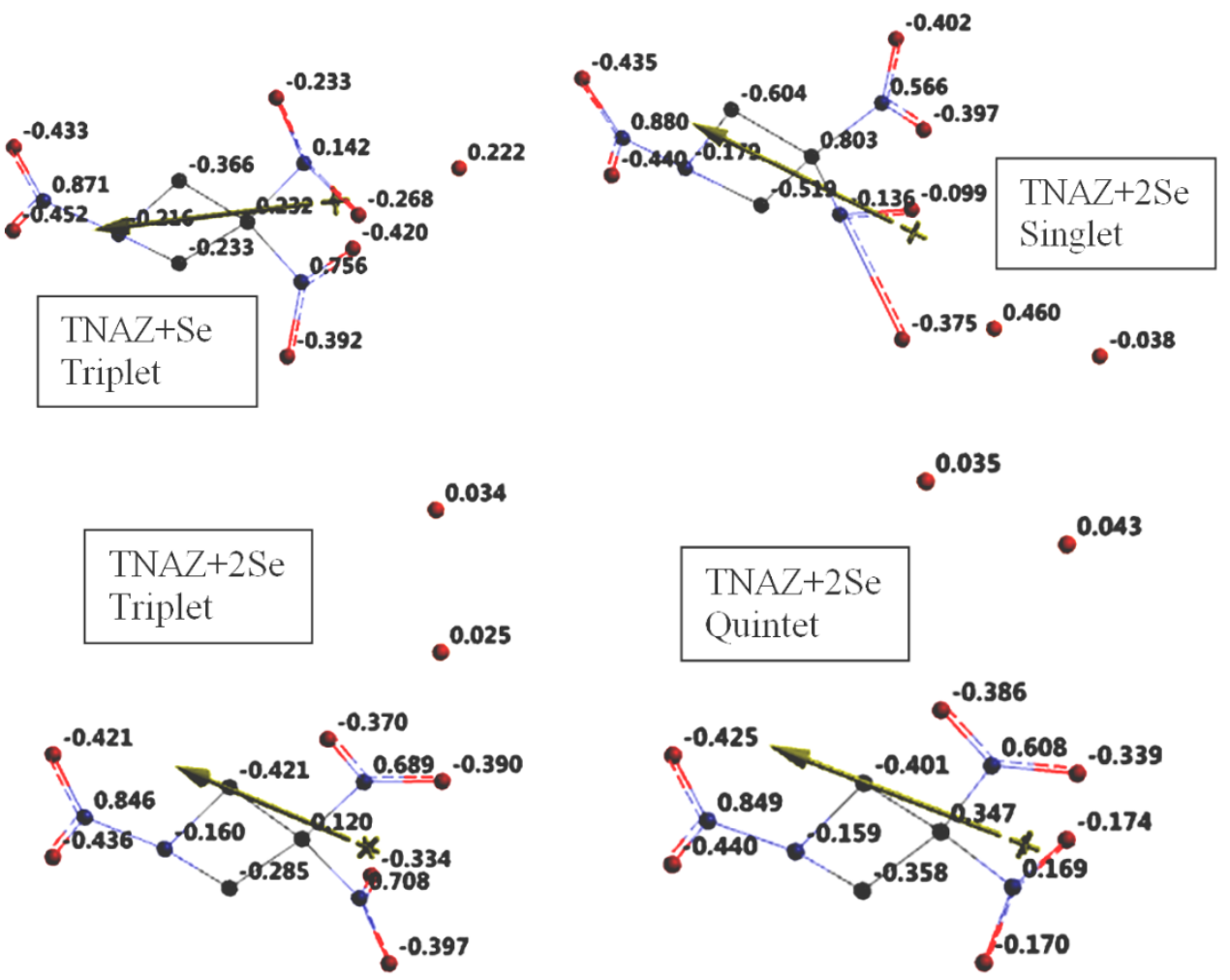

Figure 3. The ESP charges on atoms of the species considered (Hydrogens omitted, in $\AA$ units).

Table 2 displays some energies of the species considered where E, ZPE and $\mathrm{E}_{\mathrm{C}}$ stand for total electronic energy, zero point vibrational energy and the corrected total electronic energy, respectively. According to the data in the table they are all electronically stable species (all have negative $\mathrm{E}_{\mathrm{c}}$ values). The stability order for TNAZ+2Se species is Triplet $>$ Singlet $>$ Quintet. 
Table 2. Some energies of the species considered.

\begin{tabular}{lccc}
\hline Specie & $\mathbf{E}$ & $\mathbf{Z P E}$ & $\mathbf{E}_{\mathbf{C}}$ \\
\hline TNAZ+Se & -8370061.29 & 276.47 & -8369784.82 \\
Triplet & & & \\
TNAZ+2Se & -14674795.82 & 274.38 & -14674521.44 \\
Singlet & & & \\
TNAZ+2Se & -14674856.94 & 282.97 & -14674573.97 \\
Triplet & & & \\
TNAZ+2Se & -14674628.32 & 275.79 & -14674352.53 \\
Quintet & & & \\
\hline
\end{tabular}

Energies in $\mathrm{kJ} / \mathrm{mol}$.

Figure 4 shows the ESP maps of the species considered which are based on the ESP charges.
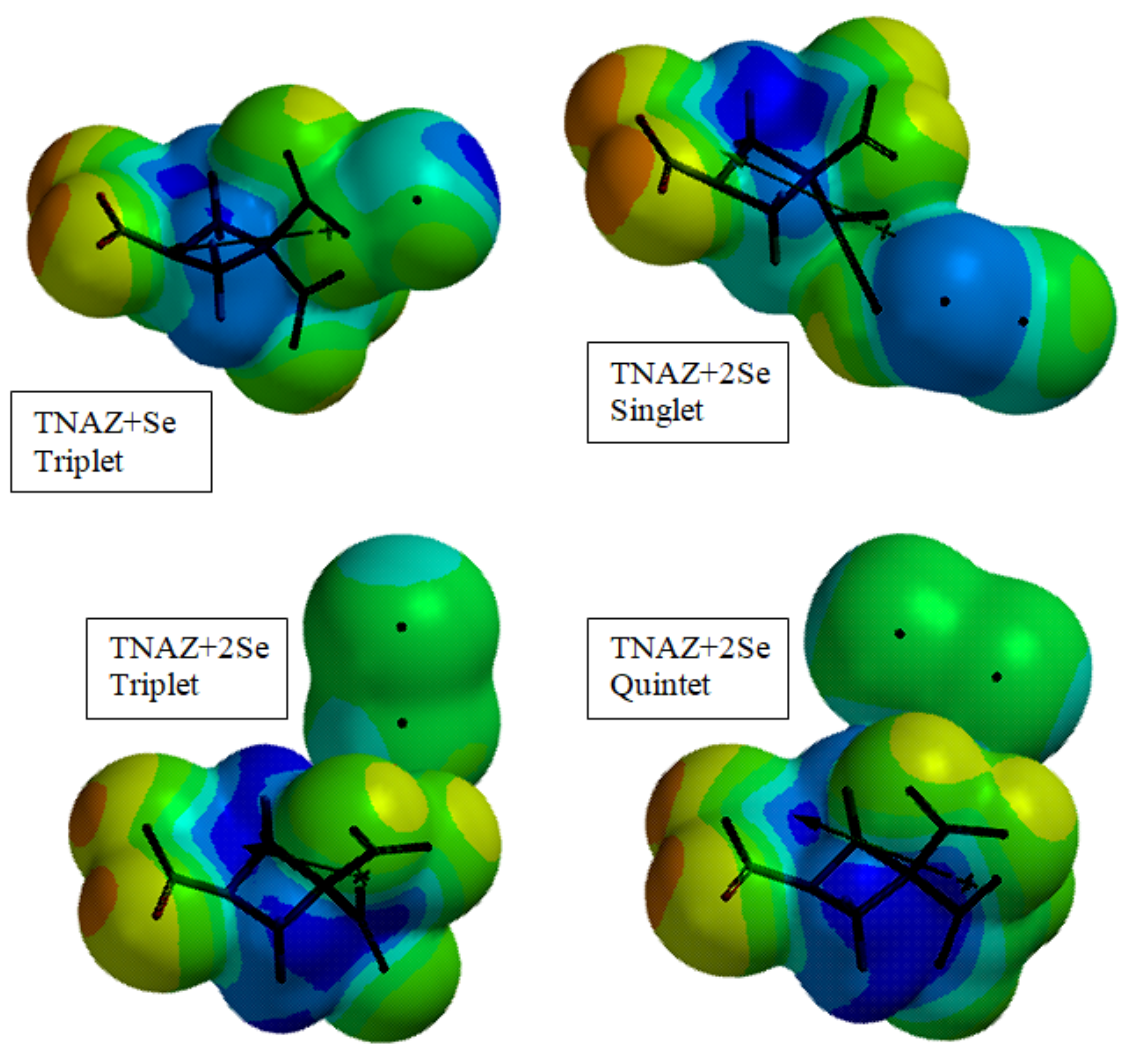

Figure 4. The electrostatic potential maps of the species considered. 
Figure 5 displays some of the molecular orbital energy levels of the species considered. Note that all the species except TNAZ+2Se (singlet) are open-shell systems. Therefore UB3LYP/6-31++G(d,p) level of calculations result in $\alpha$ - and $\beta$-type orbitals. In the figure instead of those designations $a$ and $b$ are used, respectively.

Table 3 shows the HOMO, LUMO energies and the interfrontier molecular orbital energy gap $\left(\Delta \varepsilon=\varepsilon_{\text {LUMO }}-\varepsilon_{\text {HOMO }}\right)$ values of the species considered. The HOMO energy order in the case of TNAZ $+2 \mathrm{Se}$ species is Singlet $<$ Quintet $<$ Triplet, whereas the LUMO order follows the sequence of Singlet $<$ Triplet $<$ Quintet. Note that some of the HOMOs are $\alpha$ - and some $\beta$-type. As for the $\Delta \varepsilon$ values the order is TNAZ+Se(triplet) $>$ $\mathrm{TNAZ}+2 \mathrm{Se}$ (quintet) $>\mathrm{TNAZ}+\mathrm{S} 2 \mathrm{e}$ (triplet) $>\mathrm{TNAZ}+2 \mathrm{Se}$ (singlet).
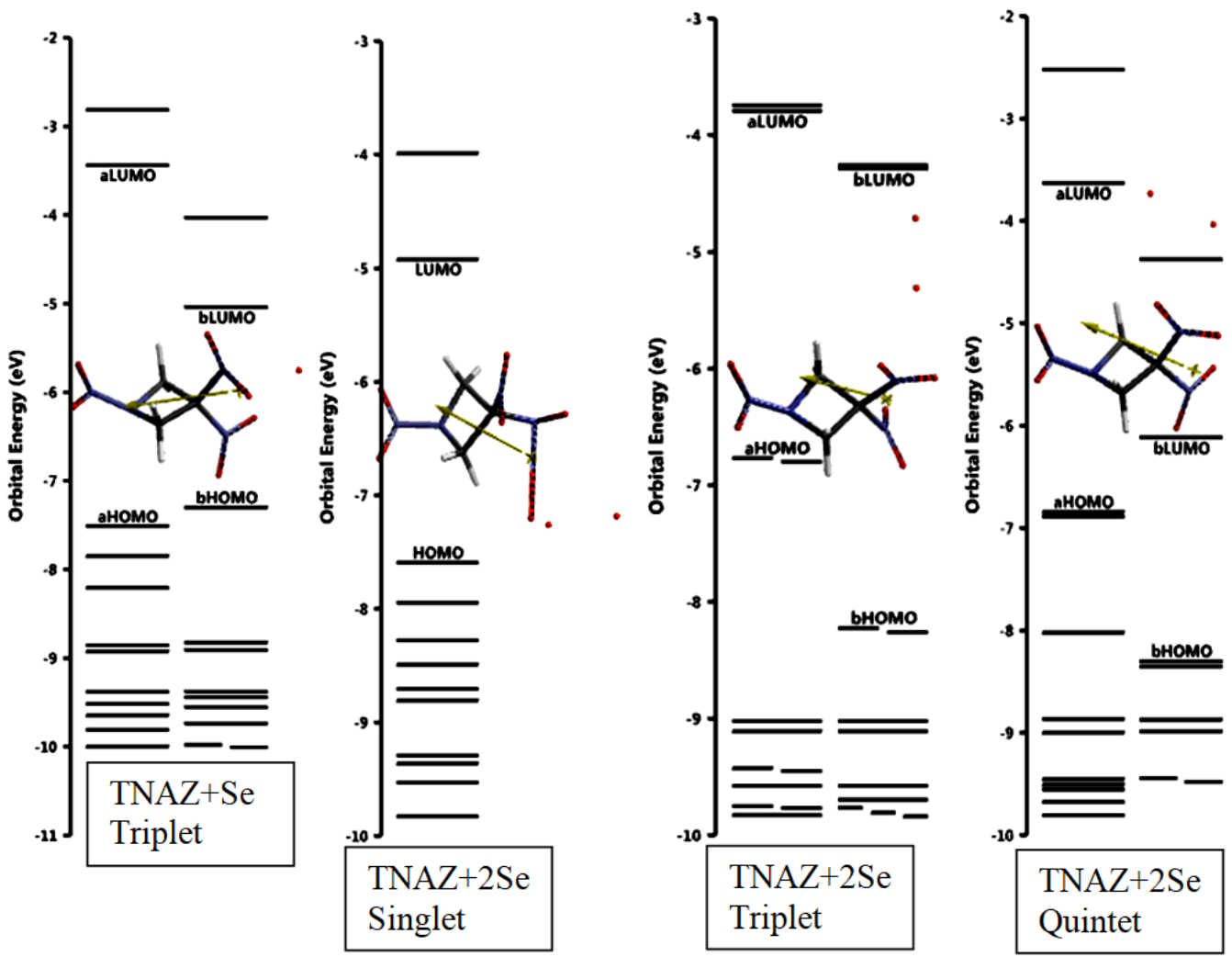

Figure 5. Some of the molecular orbital energy levels of the species considered. 
Table 3. The HOMO, LUMO energies and $\Delta \boldsymbol{\varepsilon}$ values of the species considered.

\begin{tabular}{lccc}
\hline Specie & HOMO & LUMO & $\Delta \boldsymbol{\varepsilon}$ \\
\hline $\begin{array}{l}\text { TNAZ+Se } \\
\text { Triplet }\end{array}$ & -724.87 & -331.63 & 393.24 \\
TNAZ+2Se & -732.38 & -474.79 & 257.59 \\
Singlet & & & \\
TNAZ+2Se & -652.86 & -366.02 & 286.84 \\
Triplet & & & \\
TNAZ+2Se & -660.23 & -350.30 & 309.93 \\
Quintet & & & \\
\hline
\end{tabular}

Energies in $\mathrm{kJ} / \mathrm{mol}$.

All the variations in the properties of these species should arise not only from conformation of the nitro groups of TNAZ body in the presence of selenium atom(s) or interaction between TNAZ moiety and selenium atom(s) nearby but also interaction of selenium atoms in between. The Se atoms occupy different locations nearby the geminal $\mathrm{NO}_{2}$ groups but one of them is always closer to TNAZ molecule. The distance between the Se atoms in TNAZ+2Se cases vary in between 2.201-2.202 Á. Since, Se atoms in the ground state has unpaired electrons and vacant d-orbitals various possibilities of interactions are possible.

Figure 6 shows the HOMO and LUMO patterns of TNAZ+Se (triplet). The main contribution to these frontier molecular orbitals is from the selenium atom.

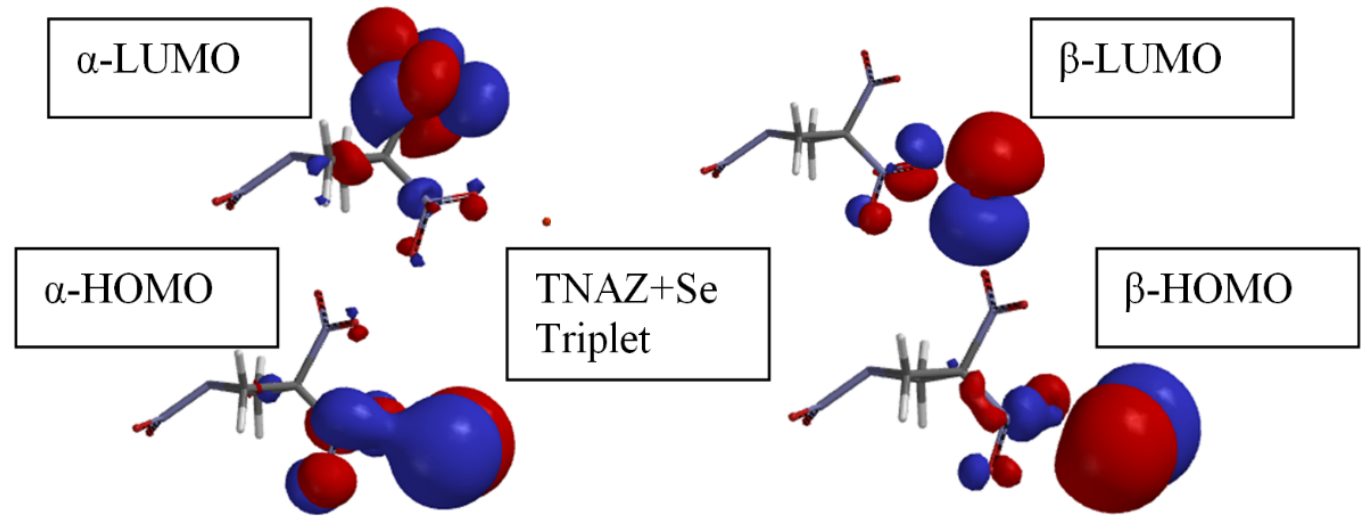

Figure 6. The HOMOs and LUMOs of TNAZ+2Se (triplet) specie. 
Figure 7 shows the HOMO and LUMO of the singlet, triplet and quintet TNAZ+2Se composites. In all the cases, TNAZ moiety supplies very little or nil into those molecular orbitals, the contributions are mainly from the selenium component.

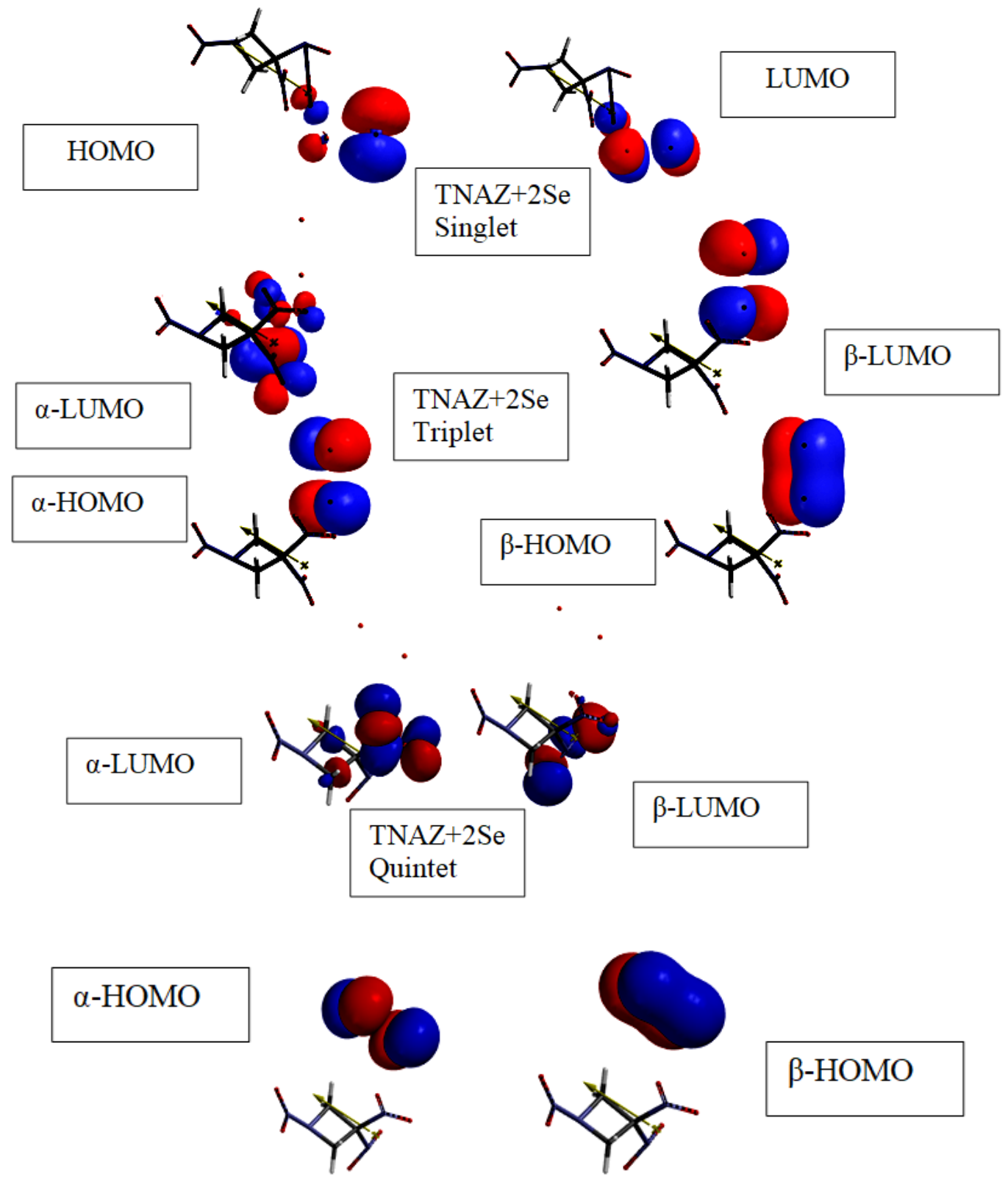

Figure 7. The HOMOs and LUMOs of TNAZ+2Se species. 
Figure 8 stands for the local ionization maps of the species considered. Note that in a local ionization potential map conventionally red regions on the density surface indicate areas from which electron removal is relatively easy, meaning that they are subject to electrophilic attack. On the other hand, regions having blue color represent areas where ionization is relatively difficult. Hence, in these structures electron removal is relatively easy from regions colored in yellow/yellowish where in the present case selenium atoms are more likely to be electron donors although they are in interaction with TNAZ moiety at different extends.
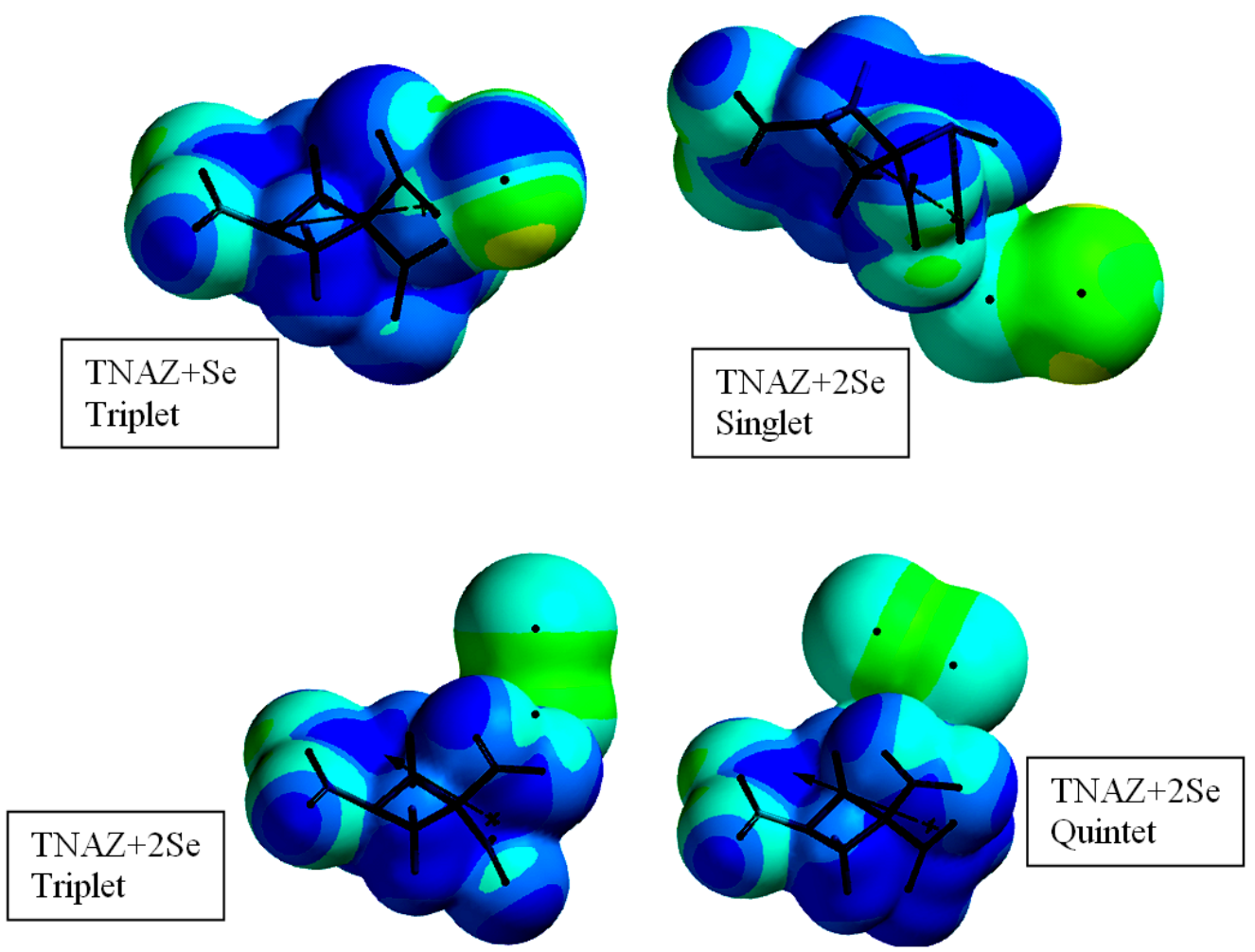

Figure 8. The local ionization maps of the species considered.

Figure 9 shows the electron density maps whereas Figure 10 stands for the spin density maps of the open-shell systems of consideration. As seen in Figure 9, in the cases of TNAZ+Se (triplet) and TNAZ+2Se (singlet) considerable degree of fusion between TNAZ molecule and the selenium(s) occurs in terms of electron density. Whereas, in the cases of TNAZ+ 2Se (triplet) and (quintet) species selenium atoms exhibit quite high electron density in between them rather than between TNAZ and selenium atoms. 

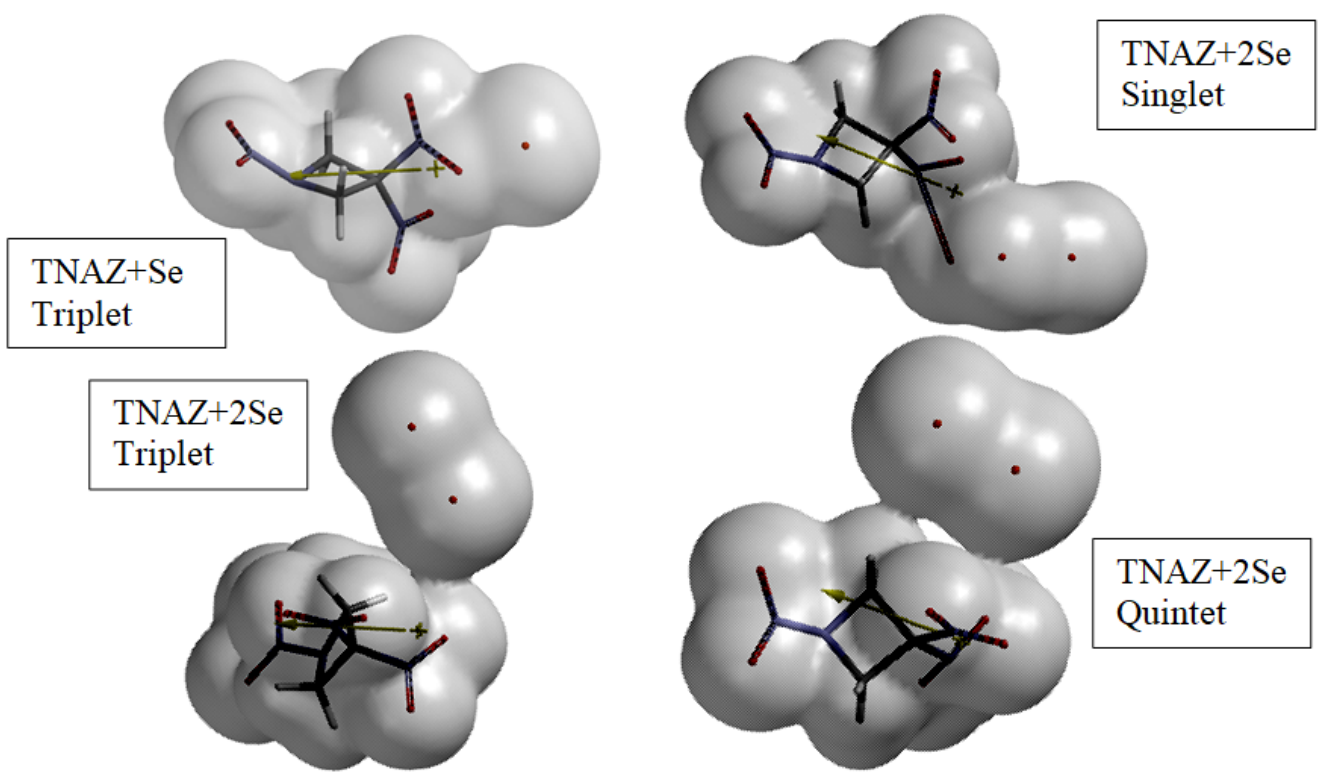

Figure 9. Electron density maps of the species considered.

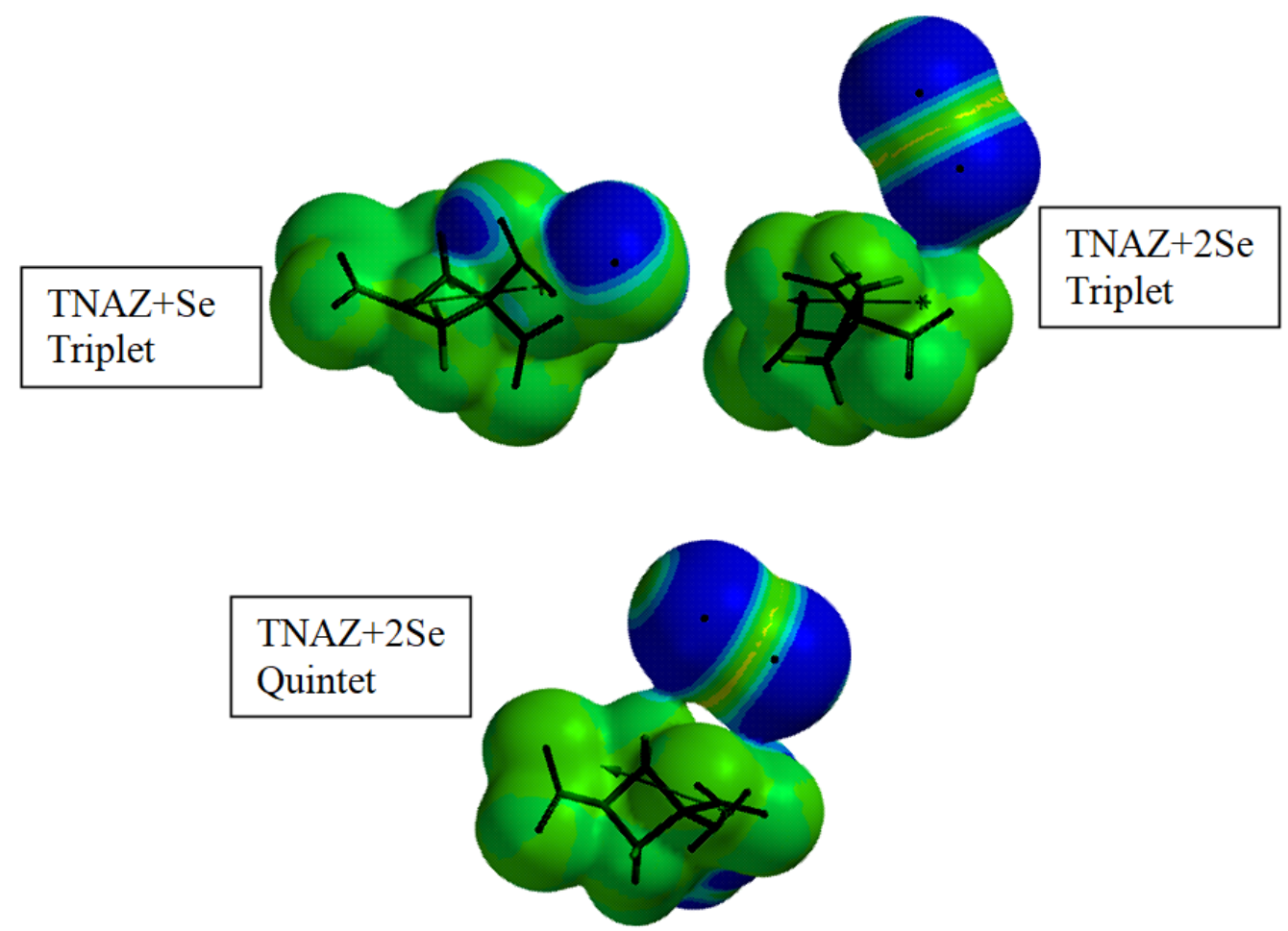

Figure 10. Spin density maps of the open-shell systems considered. 
In those systems selenium atoms should prefer to be in the form of $\mathrm{Se}_{2}$ molecule. Note that the triplet state of singly bonded $\mathrm{Se}_{2}$ is more stable than its singlet. That order is maintained in TNAZ+2Se (triplet) and TNAZ+Se (singlet) (see Table 2).

As for the spin density maps, Figure 10 indicates that selenium atom(s) transfer some spin density to TNAZ moiety in the cases of TNAZ+Se (triplet) and TNAZ+2Se (quintet).

TNAZ+2Se (singlet) case is somewhat different from the other composites considered presently, because it possesses an elongated $\mathrm{N}-\mathrm{O}$ bond which belongs to one of the geminal nitro groups. To shed some light on the issue, three models have been constructed. In model-1, the nitramine nitro group is removed. In model-2 azetidine ring has been destroyed by removing the ring nitrogen. Model-3 is 1,1-dinitrobutane structure. Figure 11 shows the optimized structures of these models obtained at the same level of calculations. Only in the case of model-1, N-O bond elongation has been observed unlike the others. Therefore, the existence of azetidine ring is essential for the occurrence of bond elongation in TNAZ+2Se (singlet) case. The nitrogen atom probably influences the electron density, thus the potential about the nitro group. In the model the distance between N-H hydrogen and N-O oxygen is $2.216 \AA$ whereas in TNAZ+2Se (singlet) distance between $\mathrm{C}-\mathrm{H}$ hydrogen and N-O oxygen is $2.467 \AA$. Note that N-H and C-H bonds both in the TNAZ+2Se composite and in model-1 do not indicate any hydrogen bonding. Thus the bond elongation is to be primarily as a result of interaction with $\mathrm{Se}$ atom(s).
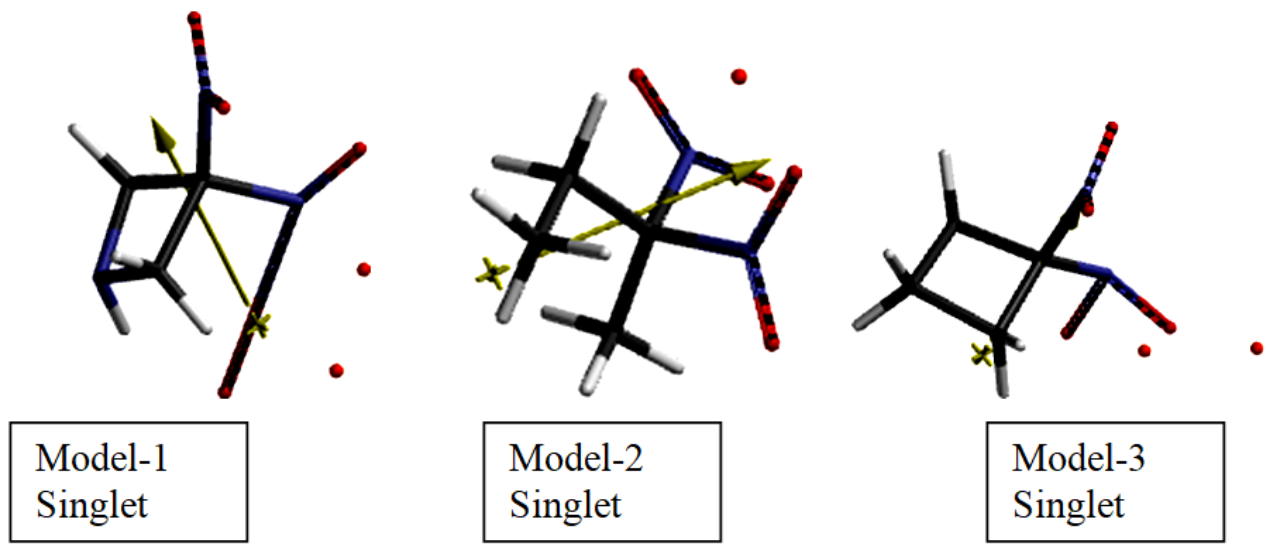

Figure 11. Some models having two atoms of selenium. 


\section{Conclusion}

The present treatise within the restrictions of density functional theory and the applied basis set has revealed that TNAZ and selenium interact with each other at different extents depending on the multiplicity states of the systems. The selenium atom(s) get(s) small positive ESP charges, except TNAZ+2Se (singlet) case in which the distant selenium atom possesses a minute negative charge. The selenium atoms have a certain type of bonding in between. The frontier molecular orbitals are mainly dictated by the selenium component(s) and the multiplicity.

\section{References}

[1] P.F. Pagoria, G.S. Lee, R.A. Mitchell and R.D. Schmidt, A review of energetic materials synthesis, Thermochim. Acta 384 (2002), 187-204. https://doi.org/10.1016/S0040-6031(01)00805-X

[2] H.S. Jadhav, M.B. Talawar, D.D. Dhavale, S.N. Asthana and V.V. Krishnamurthy, Alternate method to synthesis of 1,3,3-trinitroazetedine (TNAZ): Next generation melt castable high energy material, Indian J. Chemical Technology 13 (2006), 41-46.

[3] L. Türker, A composite of NTO and TNAZ - A DFT treatment, Earthline Journal of Chemical Sciences 5(2) (2021) 261-274. https://doi.org/10.34198/ejcs.5221.261274

[4] L. Türker, A DFT treatment of some aluminized 1,3,3-trinitroazetidine (TNAZ) systems A deeper look, Earthline Journal of Chemical Sciences 3(2) (2020), 121-140. https://doi.org/10.34198/ejcs.3220.121140

[5] T.G. Archibald, R. Gilardi, K. Baum and C.J. George, Synthesis and x-ray crystal structure of 1,3,3-trinitroazetidine, J. Org. Chem. 55 (1990), 2920-2924. https://doi.org/10.1021/jo00296a066

[6] R.L. McKenney, Jr., T.G. Floyd, W.E. Stevens, T.G. Archibald, A.P. Marchand, G.V.M. Sharma and S.G. Bott, Synthesis and thermal properties of 1,3-dinitro-3-(1',3'dinitroazetidin-3'-yl) azetidine (TNDAZ) and its admixtures with 1,3,3-trinitroazetidine (TNAZ), J. Energ. Mater. 16 (1998), 199-235. https://doi.org/10.1080/07370659808217513

[7] A.M. Hiskey, M.C. Johnson and E.D. Chavez, Preparation of 1-substituted-3,3dinitroazetidines, J. Energ. Mater. 17 (1999), 233-252. https://doi.org/10.1080/07370659908216106 
[8] J. Zhang, R. Hu, C. Zhu, G. Feng and Q. Long, Thermal behavior of 1,3,3trinitroazetidine, Thermochim. Acta 298 (1997), 31-35. https://doi.org/10.1016/S0040-6031(97)00056-7

[9] S. Zeman, The thermoanalytical study of some amino derivatives of 1,3,5trinitrobenzene, Thermochim. Acta 216 (1993), 157-168. https://doi.org/10.1016/0040-6031(93)80389-R

[10] M.H. Keshavarz, Approximate prediction of melting point of nitramines, nitrate esters, nitrate salts and nitroaliphatics energetic compounds, J. Hazard. Mater. 138 (2006), 448451. https://doi.org/10.1016/j.jhazmat.2006.05.097

[11] Z. Jalovy, S. Zeman, M. Suceska, P. Vavra, K. Dudek and J.M. Rajic, 1,3,3Trinitroazetidine (TNAZ). Part I. Syntheses and properties, J. Energ. Mater. 19 (2001), 219-239. https://doi.org/10.1080/07370650108216127

[12] D.S. Watt and M.D. Cliff, Evaluation of 1,3,3-trinitroazetidine (TNAZ) - A high performance melt-castable explosive, Technical Report DSTO-TR-1000, Defence Science and Technology Organization (DSTO), Aeronautical and Maritime Research Laboratory, Melbourne, Australia, 2000.

[13] A.K. Sikder and N. Sikder, A review of advanced high performance, insensitive and thermally stable energetic materials emerging for military and space applications, $J$. Hazard. Mater. 112 (2004), 1-15. https://doi.org/10.1016/j.jhazmat.2004.04.003

[14] S. Iyer, E. Y. Sarah, M. Yoyee, R. Perz, J. Alster and D. Stoc, TNAZ based composition C-4 development, $11^{\text {th }}$ Annual Working Group, Institute on Synthesis of High Density Materials (Proc.), Kiamesha Lakes, 1992.

[15] M. Oftadeh, M. Hamadanian, M. Radhoosh and M.H. Keshavarz, DFT molecular orbital calculations of initial step in decomposition pathways of TNAZ and some of its derivatives with $-\mathrm{F},-\mathrm{CN}$ and -OCH3 groups, Computational and Theoretical Chemistry 964 (2011), 262-268. https://doi.org/10.1016/j.comptc.2011.01.007

[16] J.O. Doali, R.A. Fifer, D.I. Kruzezynski and B.J. Nelson, The mobile combustion diagnostic fixture and its application to the study of propellant combustion Part-I. Investigation of the low pressure combustion of LOVA XM-39 Propellant, Technical Report No: BRLMR-3787/5, US Ballistic Research Laboratory, Maryland, 1989.

[17] J.P. Agrawal, Recent trends in high-energy materials, Prog. Energ. Combust. Sci. 24/1 (1998), 1-30. https://doi.org/10.1016/S0360-1285(97)00015-4 
[18] M.D. Coburn, M.A. Hiskey and T.G. Archibald, Scale-up and waste minimization of the Los Alamos process for 1,3,3-trinitroazetidine (TNAZ), Waste Management 17 (1997), 143-146. https://doi.org/10.1016/S0956-053X(97)10013-7

[19] L. Jizhen, F. Xuezhong, F. Xiping, Z. Fengqi and H. Rongzu, Compatibility study of 1,3,3-trinitroazetidine with some energetic components and inert materials, Journal of Thermal Analysis and Calorimetry 85(3) (2006), 779-784.

https://doi.org/10.1007/s10973-005-7370-8

[20] L. Türker and S. Varis, Desensitization of TNAZ via molecular structure modification and explosive properties - A DFT study, Acta Chim. Slov. 59 (2012), 749-759.

[21] P.J. Durant and B. Durant, Introduction to Advanced Inorganic Chemistry, London: Longman, 1972.

[22] T. Moeller, Inorganic Chemistry, New York: Wiley, 1958.

[23] D.F. Shriver, P.W. Atkins, C.H. Langford, Inorganic Chemistry, Oxford: Oxford, 1990.

[24] J.J.P. Stewart, Optimization of parameters for semiempirical methods I. Method, $J$. Comput. Chem. 10 (1989), 209-220. https://doi.org/10.1002/jcc.540100208

[25] J.J.P. Stewart, Optimization of parameters for semi empirical methods II. Application, $J$. Comput. Chem. 10 (1989), 221-264. https://doi.org/10.1002/jcc.540100209

[26] A. R. Leach, Molecular Modeling, Essex: Longman, 1997.

[27] P. Fletcher, Practical Methods of Optimization, New York: Wiley, 1990.

[28] W. Kohn and L. Sham, Self-consistent equations including exchange and correlation effects, J. Phys. Rev. 140 (1965), A1133-A1138. https://doi.org/10.1103/PhysRev.140.A1133

[29] R.G. Parr and W. Yang, Density Functional Theory of Atoms and Molecules, London: Oxford University Press, 1989.

[30] C.J. Cramer, Essentials of Computational Chemistry, Chichester, West Sussex: Wiley, 2004.

[31] A.D. Becke, Density-functional exchange-energy approximation with correct asymptotic behavior, Phys. Rev. A 38 (1988), 3098-3100. https://doi.org/10.1103/PhysRevA.38.3098

[32] S.H. Vosko, L. Wilk and M. Nusair, Accurate spin-dependent electron liquid correlation energies for local spin density calculations: a critical analysis, Can. J. Phys. 58 (1980), 1200-1211. https://doi.org/10.1139/p80-159 
[33] C. Lee, W. Yang and R.G. Parr, Development of the Colle-Salvetti correlation energy formula into a functional of the electron density, Phys. Rev. B 37 (1988), 785-789. https://doi.org/10.1103/PhysRevB.37.785

[34] SPARTAN 06, Wavefunction Inc., Irvine CA, USA, 2006.

[35] V.I. Minkin, R.M. Minyaev and Yu.A. Zhdanov, Nonclassical Structurs of Organic Compounds, Moscow: Mir, 1987. 